INFLAMMATORY BOWEL DISEASE

\title{
Synergy between TLR9 and NOD2 innate immune responses is lost in genetic Crohn's disease
}

\author{
D A van Heel, S Ghosh, K A Hunt, C G Mathew, A Forbes, D P Jewell, R J Playford
}

Gut 2005;54:1553-1557. doi: 10.1136/gut.2005.065888

See end of article for authors' affiliations

Correspondence to:

Dr A van Heel, Intestinal Inflammation and Repair Group, Department of Gastroenterology, Imperial College London,

Hammersmith Campus,

London W12 ONN, UK;

d.vanheel@imperial.ac.uk

Revised version received 15 April 2005

Accepted for publication

5 May 2005

Published online first

31 May 2005
Background: Nucleotide binding oligomerisation domain 2 (NOD2; also known as CARD15) mutations are associated with Crohn's disease but how mutations cause disease is poorly understood. Innate immune responses are reportedly enhanced by combined NOD2 ligand (muramyl dipeptide, MDP) and Toll-like receptor 4 ligand (TLR4, lipopolysaccharide) stimulation. Intestinal TLR signalling has a dual rolemaintaining intestinal homeostasis and protection from injury as well as initiating inflammatory responses. TLR9 is functional in the intestinal epithelium where it is most strongly expressed in Paneth cells.

Aims: To study possible interactions between CpG DNA (TLR9 ligand) and MDP using primary human cells of differing NOD2 genotypes.

Subjects: NOD2 wild-type healthy controls $(n=7)$ and NOD2 homozygous Crohn's disease patients $(n=19)$, age and sex matched.

Methods: Peripheral blood mononuclear cells were stimulated with CpG DNA and MDP. Cytokines were measured by enzyme linked immunosorbent assay.

Results: Tumour necrosis factor $\alpha$ (TNF- $\alpha$ ) and interleukin 8 (IL-8) responses to CpG DNA were similar in NOD2 wild-type and homozygous mutant cells. Concomitant NOD2 stimulation had a marked synergistic effect on CpG DNA induced TNF- $\alpha$ responses at 10-100 ng/ml MDP. A mean 2.1-fold increase in CpG DNA induced TNF- $\alpha$ responses and a mean 3.7-fold increase in IL-8 responses were observed in NOD2 wild-type cells with $10 \mathrm{ng} / \mathrm{ml}$ MDP. This effect was abolished in NOD2 homozygous cells.

Conclusions: NOD2 stimulation normally enhances innate immune responses to CpG DNA. This marked synergistic effect is lost in Crohn's disease patients homozygous for NOD2 mutations, with implications for TLR mediated intestinal homeostasis and inflammation.
$\mathrm{T}$ oll-like receptors (TLRs) are a family of pattern recognition receptors that sense conserved motifs found in microbial pathogens. TLRs detect microbial infection and initiate immune defense against pathogens. An additional innate immune receptor family, the intracellular NOD proteins, has recently been shown to recognise bacterial peptidoglycan breakdown products but within the cytosol in contrast with membrane bound TLR recognition. ${ }^{1}$ Mutations in the nucleotide binding oligomerisation domain 2 (NOD2, also known as CARD15) gene have been strongly associated with Crohn's disease in multiple Caucasian populations, with the strongest effect in individuals carrying mutated forms of

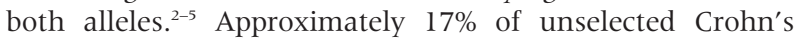
disease patients are homozygous for known NOD2 variants, the majority of homozygotes comprising three common NOD2 mutations. ${ }^{6}$ Functional studies have been mainly performed using plasmid transfected cell lines or mouse models, and a few using primary human patient derived material. How NOD2 mutations lead to Crohn's disease remains unclear, although cell line studies have shown mutations impair activation of nuclear factor kappa B (NFKB).

Synergistic enhancement of lipopolysaccharide (a TLR4 ligand) responses by muramyl dipeptide (MDP, now known to be a NOD2 ligand) has been reported..$^{7}$ Recent reports have shown synergy between NOD2 activation and several TLR ligands in cellular responses. ${ }^{9}{ }^{10}$ We were particularly interested in possible interactions between TLR9 and NOD2, as TLR9 appears to have a special role in intestinal immune responses and the effect of stimulating these receptors has not been studied in Crohn's disease patient samples. We collected primary peripheral blood mononuclear cells (PBMCs) from controls and Crohn's disease patients homo- zygous for NOD2 mutations in order to study responses to TLR9 and NOD2 ligands in detail.

\section{METHODS \\ Subjects}

PBMCs were prepared by density gradient centrifugation (Lymphoprep; Nycomed, Oslo, Norway) of heparinised venous blood. Blood samples were collected after written informed consent was given and with local research ethics committee approval. All subjects were white UK Caucasian (table 1).

DNA extraction from peripheral blood and polymerase chain reaction-restriction fragment length polymorphic genotyping for the three common NOD2 variants was performed as described previously. ${ }^{11}$ All Crohn's disease patient samples were also genotyped in duplicate in other laboratories using separately collected DNA samples with identical results. ${ }^{1-13}$

\section{Cell culture}

Cytokine studies were performed using $2 \times 10^{5}$ PBMCs cultured for 22 hours in $250 \mu \mathrm{l}$ media (including ligands) per well in 96 well plates. In some experiments, cryopreserved liquid nitrogen stored PBMCs were used to permit parallel culture followed by enzyme linked immunosorbent assay (ELISA) assay of hard to collect patient cells. Cryopreservation was according to a method reported to

Abbreviations: ELISA, enzyme linked immunosorbent assay; IL, interleukin; LPMC, lamina propria mononuclear cells; LPS, lipopolysaccharide; MDP, muramyl dipeptide (MurNAc-L-Ala-D-isoGln); NFKB, nuclear factor kappa B; NOD2, nucleotide binding oligomerisation domain 2 (also known as CARD15); PBMC, peripheral blood mononuclear cell; TLR, toll-like receptor; TNF- $\alpha$, tumour necrosis factor $\alpha$ 
Table 1 Characteristics of the subjects studied

\begin{tabular}{|c|c|c|c|c|c|c|c|c|}
\hline \multirow[b]{2}{*}{ Subject } & \multirow[b]{2}{*}{ NOD2 status } & \multirow[b]{2}{*}{ Sex } & \multicolumn{3}{|c|}{ At time of venesection } & \multicolumn{3}{|c|}{ Disease classification* } \\
\hline & & & $\begin{array}{l}\text { Age } \\
(y)\end{array}$ & IBD drugs & Activity & $\begin{array}{l}\text { Age at } \\
\text { diagnosis }(y)\end{array}$ & Location & Behaviour \\
\hline $\mathrm{HCl}$ & wt/wt & $M$ & 31.8 & - & & & & \\
\hline $\mathrm{HC} 2$ & wt/wt & $\mathrm{F}$ & 49.1 & - & & & & \\
\hline HC3 & wt/wt & $\mathrm{F}$ & 38.4 & - & & & & \\
\hline $\mathrm{HC} 4$ & wt/wt & $\mathrm{F}$ & 37.3 & - & & & & \\
\hline HC5 & wt/wt & $M$ & 46.0 & - & & & & \\
\hline HC6 & wt/wt & $M$ & 30.3 & - & & & & \\
\hline $\mathrm{HC7}$ & wt/wt & $M$ & 27.9 & - & & & & \\
\hline CDI & $1007 f_{s} / 1007 f_{s}$ & $\mathrm{~F}$ & 36.1 & Nil & Quiescent & $<40$ & Ileocolon & Penetrating \\
\hline $\mathrm{CD} 2$ & $1007 \mathrm{fs}_{\mathrm{s}} / 1007 \mathrm{fs}$ & $\mathrm{F}$ & 77.8 & $\mathrm{Nil}$ & Quiescent & $\geqslant 40$ & lleal & Stricturing \\
\hline CD3 & $1007 \mathrm{fs} / 1007 \mathrm{fs}$ & $M$ & 51.3 & Nil & Quiescent & $<40$ & lleal & Stricturing \\
\hline CD4 & $1007 \mathrm{fs} / 1007 \mathrm{fs}$ & $M$ & 27.0 & 5-ASA, prednisolone & Active & $<40$ & lleal & Stricturing \\
\hline CD5 & $908 \mathrm{Arg} / 1007 \mathrm{fs}$ & $M$ & 23.0 & Nil & Quiescent & $<40$ & Ileal & Penetrating \\
\hline CD6 & $908 \mathrm{Arg} / 1007 \mathrm{fs}$ & $\mathrm{F}$ & 36.6 & 5-ASA & Quiescent & $<40$ & lleal & Penetrating \\
\hline CD7 & $908 \mathrm{Arg} / 1007 \mathrm{fs}$ & $\mathrm{F}$ & 59.3 & Nil & Quiescent & $<40$ & Ileal & Stricturing \\
\hline CD8 & $908 \mathrm{Arg} / 1007 \mathrm{fs}$ & $M$ & 55.9 & Nil & Quiescent & $<40$ & Ileocolon & Penetrating \\
\hline CD9 & $702 \mathrm{Trp} / 1007 \mathrm{fs}$ & $\mathrm{F}$ & 30.9 & $\mathrm{Nil}$ & Quiescent & $<40$ & Upper GI & Stricturing \\
\hline CD10 & $702 \mathrm{Trp} / 1007 \mathrm{fs}$ & $\mathrm{F}$ & 56.3 & Prednisolone & Quiescent & $<40$ & Ileocolon & Stricturing \\
\hline CD11 & $702 \mathrm{Trp} / 1007 \mathrm{fs}$ & $\mathrm{F}$ & 42.4 & Nil & Quiescent & $<40$ & lleal & Stricturing \\
\hline CD12 & $702 \mathrm{Trp} / 1007 \mathrm{fs}$ & $M$ & 19.2 & Azathioprine & Quiescent & $<40$ & Ileocolon & Stricturing \\
\hline CD13 & $702 \mathrm{Trp} / 1007 \mathrm{fs}$ & $\mathrm{F}$ & 32.6 & Azathioprine & Quiescent & $<40$ & lleal & Stricturing \\
\hline CD14 & $702 \mathrm{Trp} / 1007 \mathrm{fs}$ & $M$ & 41.1 & Nil & Quiescent & $<40$ & lleal & Stricturing \\
\hline CD15 & 702Trp/702Trp & $M$ & 46.9 & $\mathrm{Nil}$ & Quiescent & $<40$ & lleal & Penetrating \\
\hline CD16 & 702Trp/702Trp & $\mathrm{F}$ & 63.2 & $\mathrm{Nil}$ & Quiescent & $\geqslant 40$ & lleal & Stricturing \\
\hline $\mathrm{CD} 17$ & 702Trp/702Trp & $\mathrm{F}$ & 48.1 & $\mathrm{Nil}$ & Quiescent & $\geqslant 40$ & lleal & Stricturing \\
\hline CD18 & 702Trp/702Trp & $M$ & 28.2 & Azathioprine & Active & $<40$ & Upper GI & Penetrating \\
\hline CD19 & 702Trp/702Trp & $\mathrm{F}$ & 31.3 & 5-ASA & Quiescent & $<40$ & lleal & Stricturing \\
\hline
\end{tabular}

yield similar results in overnight cytokine assays to fresh cells $^{14}$ (and confirmed in our laboratory-data not shown). Serum free X-VIVO 15 media (optimised for lymphocyte/ monocyte culture) with gentamicin $(50 \mu \mathrm{g} / \mathrm{ml})$ was used for all experiments (Cambrex BioScience, Wokingham, UK). All conditions were tested in duplicate.

Synthetic pharmaceutical grade muramyl dipeptide (MDPLys $_{18}$, Nopia/romurtide; Daiichi Pharmaceutical, Japan), NOD2 ligand, was used at $1-100 \mathrm{ng} / \mathrm{ml}$ ( $10 \mathrm{ng}$ / $\mathrm{ml}=11 \mathrm{nM}$ ). Synthetic phosphorothioate stabilised unmethylated CpG DNA, TLR9 ligand, containing both type A and type B immunostimulatory sequences (ODN M362, 5' TCG TCG TCG TTC GAA CGA CGT TGA T-3'; Invivogen, San Diego, California, USA) or control non-CpG DNA containing reversed CG base pairs (ODN M362C/M383, 5' -TGC TGC TGC TTG CAA GCA GCT TGA T-3'; Invivogen) were used at 0.1$10 \mu \mathrm{g} / \mathrm{ml}(10 \mu \mathrm{g} / \mathrm{ml}=1.2 \mu \mathrm{M})$. All ligands were endotoxin tested (negative). Gel purified lipopolysaccharide (LPS) from Escherichia coli 055:B5 (TLR4 ligand, L2637; Sigma, Poole, UK) at $1 \mathrm{ng} / \mathrm{ml}$ was used as a positive control to induce cytokine secretion.

\section{ELISA}

Cell culture supernatants were used at 1 part in 2 dilution (tumour necrosis factor $\alpha($ TNF- $\alpha$ ), interleukin (IL)-1 $\beta$ ), 1 part in 4 (IL-10), or 1 part in 20 (IL-8) in 96 well plate sandwich ELISA. TNF- $\alpha$ ELISA was performed using a kit as per the manufacturer's instructions (Bender MedSystems, Vienna, Austria). IL-1 $\beta$, IL-8, and IL-10 ELISA were performed using matched monoclonal antibodies at $1 / 400$ dilutions (AL-Immunotools, Friesoythe, Germany), streptavidin-horseradish peroxidase (R\&D Systems, Abingdon, UK) and TMB- $\mathrm{H}_{2} \mathrm{O}_{2}$ (BD Bioscience, Oxford, UK). Plates were read at $450 \mathrm{nM}$ with $620 \mathrm{nM}$ correction.

\section{Statistical analysis}

The mean of duplicate culture/ELISA results were used for analysis of each individual/condition. Data are presented as mean (SEM). For comparison of multiple conditions, we used ANOVA analysis with post hoc Dunnett's or Tukey's test (as appropriate). An unpaired Student's $t$ test was used for comparison of cytokine responses, and age at venesection between NOD2 wild-type and mutant cells. Male/female ratios were compared by Fisher's exact test. Prism 4 software was used for statistical analyses (GraphPad, San Diego, California, USA). Significance level was $\mathrm{p}<0.05$.

\section{RESULTS}

Initial studies in two healthy individuals showed significant PBMC TNF- $\alpha$ responses to CpG DNA (ANOVA $p<0.0001$ for both individuals, excluding LPS from analysis) (fig 1A). Further studies of $\mathrm{CpG}$ DNA were performed at the concentration $(10 \mu \mathrm{g} / \mathrm{ml})$ giving the strongest response. PBMC TNF- $\alpha$ responses to control DNA and CpG DNA in six healthy individuals were compared (ANOVA $p=0.002$ ) (fig 1B). Significant differences were seen between CpG DNA stimulated cells and media alone (post hoc $\mathrm{p}<0.01$ ), and between CpG DNA and control DNA (post hoc $\mathrm{p}<0.05$ ), but not between control DNA and media alone (post hoc $\mathrm{p}>0.05)$. These data are consistent with receptor specific effects of M362 CpG DNA, as originally described. ${ }^{15}$

We then studied cells from NOD2 wt/wt healthy controls ( $\mathrm{n}=7$; four males/three females; mean age 37.3 (3.0)) (table 1) and NOD2 double mutant Crohn's patients $(\mathrm{n}=19$; eight males/11 females; mean age 42.5 (3.5)). There was no significant difference in age or sex distribution between groups.

We analysed TNF- $\alpha$ responses in $n=7$ wild-type PBMCs to combined stimulation with CpG DNA and different doses of MDP (fig 2A, B) and found a significant synergistic effect (ANOVA $\mathrm{p}<0.0001$ ). Post hoc analysis demonstrated that TNF- $\alpha$ responses to $\mathrm{CpG}+\mathrm{MDP}$ were significantly different from $\mathrm{CpG}$ alone (after subtraction of media or MDP results alone) (fig 2B) at $10 \mathrm{ng} / \mathrm{ml} \mathrm{MDP}(\mathrm{p}<0.01$; mean 2.1 (0.3)fold increase) and $100 \mathrm{ng} / \mathrm{ml} \mathrm{MDP}(\mathrm{p}<0.01$; mean 2.7 (0.5)fold increase). 

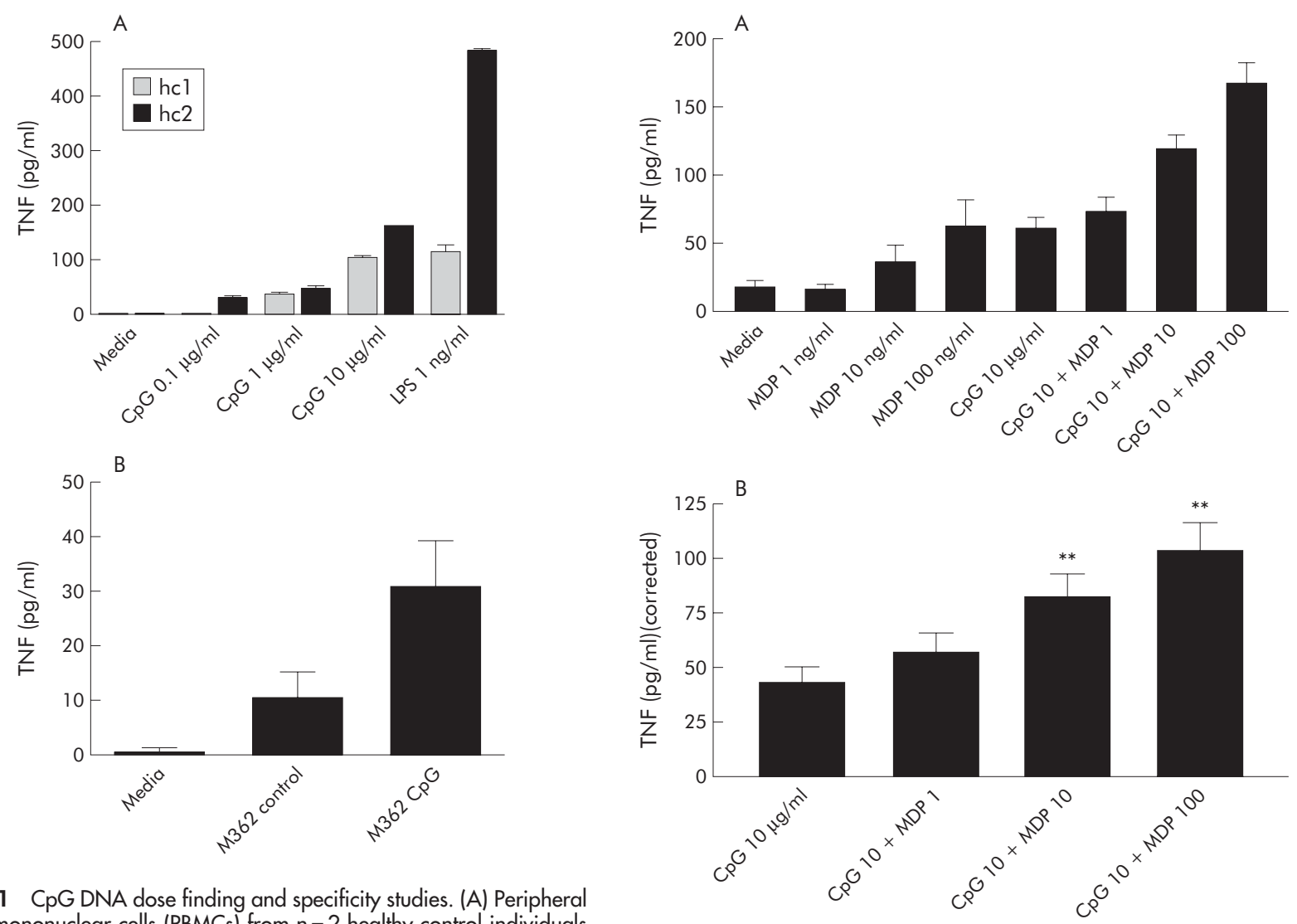

Figure 1 CpG DNA dose finding and specificity studies. (A) Periphera blood mononuclear cells (PBMCs) from $n=2$ healthy control individuals (hcl, hc2) were stimulated with M362 CpG DNA 0.1-10 $\mu \mathrm{g} / \mathrm{ml}$ and with lipopolysaccharide (LPS $1 \mathrm{ng} / \mathrm{ml}$; positive control), and tumour necrosis factor $\alpha$ (TNF) measured by enzyme linked immunosorbent assay (ELISA). (B) PBMCs from $n=6$ healthy control individuals were stimulated with M362 CpG DNA or with control M362C DNA at $10 \mu \mathrm{g} / \mathrm{ml}$ and TNF measured by ELISA.

We next studied cells of differing NOD2 genotypes, and chose the $10 \mathrm{ng} / \mathrm{ml}$ dose of MDP as this was the minimal dose to significantly enhance $\mathrm{CpG}$ responses and previous work showed maximal differences between NOD2 wild-type and mutant cells at this concentration. ${ }^{9}{ }^{16}$ A synergistic effect of MDP on CpG DNA induced TNF- $\alpha$ and IL-8 secretion was observed in wild-type PBMC ( $\mathrm{n}=7$, fig 3$)$ : after correction for media/MDP alone, MDP ( $10 \mathrm{ng} / \mathrm{ml})$ cotreatment induced a mean $2.1(0.3)$-fold increase in TNF- $\alpha$ responses $(p=0.005)$ and $3.7(0.7)$-fold increase in IL-8 responses $(p=0.02)$ to CpG DNA $(10 \mu \mathrm{g} / \mathrm{ml})$ in NOD2 wild-type PBMCs. No significant synergistic effect of MDP on CpG DNA induced TNF- $\alpha(P=0.43)$ or IL-8 secretion $(p=0.57)$ was seen in NOD2 mutant PBMCs $(\mathrm{n}=19)$. No significant differences in TNF or IL-8 cytokine responses to CpG DNA alone (corrected for media) were seen between NOD2 wild-type and NOD2 mutant PBMCs: TNF- $\alpha 43.2$ (6.7) pg/ml, 27.2 (4.1), respectively $(\mathrm{p}=0.06)$ and IL-8 547.7 (66.8) pg/ml, 435.3 (83.4) $(\mathrm{p}=0.44)$; between all five different NOD2 genotype groups (TNF- $\alpha$ ANOVA $\mathrm{p}=0.28$; IL-8 $\mathrm{p}=0.57$ ); or between Crohn's disease patients on $(n=5)$ or off $(n=14)$ immunosuppression (azathioprine/prednisolone, IL-8 $\quad \mathrm{p}=0.16$; TNF- $\alpha$ $\mathrm{p}=0.53)$ ).

We further assayed IL-1 $\beta$ and IL-10 secretion and found minimal PBMC responses to $10 \mu \mathrm{g} / \mathrm{ml}$ CpG DNA ( \pm MDP), although present with LPS control (data not shown).

\section{DISCUSSION}

In this study we demonstrated, using primary human cells of differing NOD2 genotypes, that NOD2 stimulation normally

Figure 2 Synergistic interaction between $\mathrm{CpG}$ DNA and muramyl dipeptide (MDP). Peripheral blood mononuclear cells (PBMCs) from $n=7$ NOD2 wild-type healthy control individuals were stimulated with M362 CpG DNA $10 \mu \mathrm{g} / \mathrm{ml}$ and MDP $1-100 \mathrm{ng} / \mathrm{ml}$. Tumour necrosis factor $\alpha$ (TNF) was measured by enzyme linked immunosorbent assay. Results are shown uncorrected (A) or to make obvious synergy (B) corrected by subtraction of media/MDP baseline responses. ${ }^{* *} p<0.01$, ANOVA post hoc testing.

synergistically enhances TLR9 responses (TNF- $\alpha$ and IL-8 secretion) and that synergy is lost in Crohn's disease associated NOD2 homozygotes.

We chose to use primary cells from patients and controls rather than plasmid transfected immortalised cell lines in order to study signalling in the presence of true Crohn's disease patient NOD2 mutations, physiological NOD2 and TLR expression levels, and relevant NOD2 and TLR interacting proteins. It is not yet known whether the primary defect in NOD2 associated Crohn's disease is in cells of the immune system (that is, haematopoietic) or of epithelial lineage. Because primary intestinal epithelial cells are fastidious and undergo rapid apoptosis in culture, we therefore chose PBMCs which could also be cryopreserved to allow parallel comparisons of cell culture/cytokine analyses from individuals of differing NOD2 genotypes. We were also careful to select high purity synthetic ligands, and test for endotoxin levels, to avoid the potential for misleading results in TLR studies due to contaminating biologically active impurities.

The comparison in this study was between NOD2 wild-type and NOD2 homozygotes. Heterozygotes were not studied because (i) these cannot be identified with certainty due to rare variants (known rare variants comprise $24 \%$ of NOD2 homozygotes $^{6}$ ) and (ii) the possibility that true heterozygotes may have no or minimal functional alterations. ${ }^{16} \mathrm{Li}$ et al reported no difference between wild-type and heterozygous individuals in MDP stimulated PBMC IL-8 secretion, and hypothesised that the genetic and biological data are 

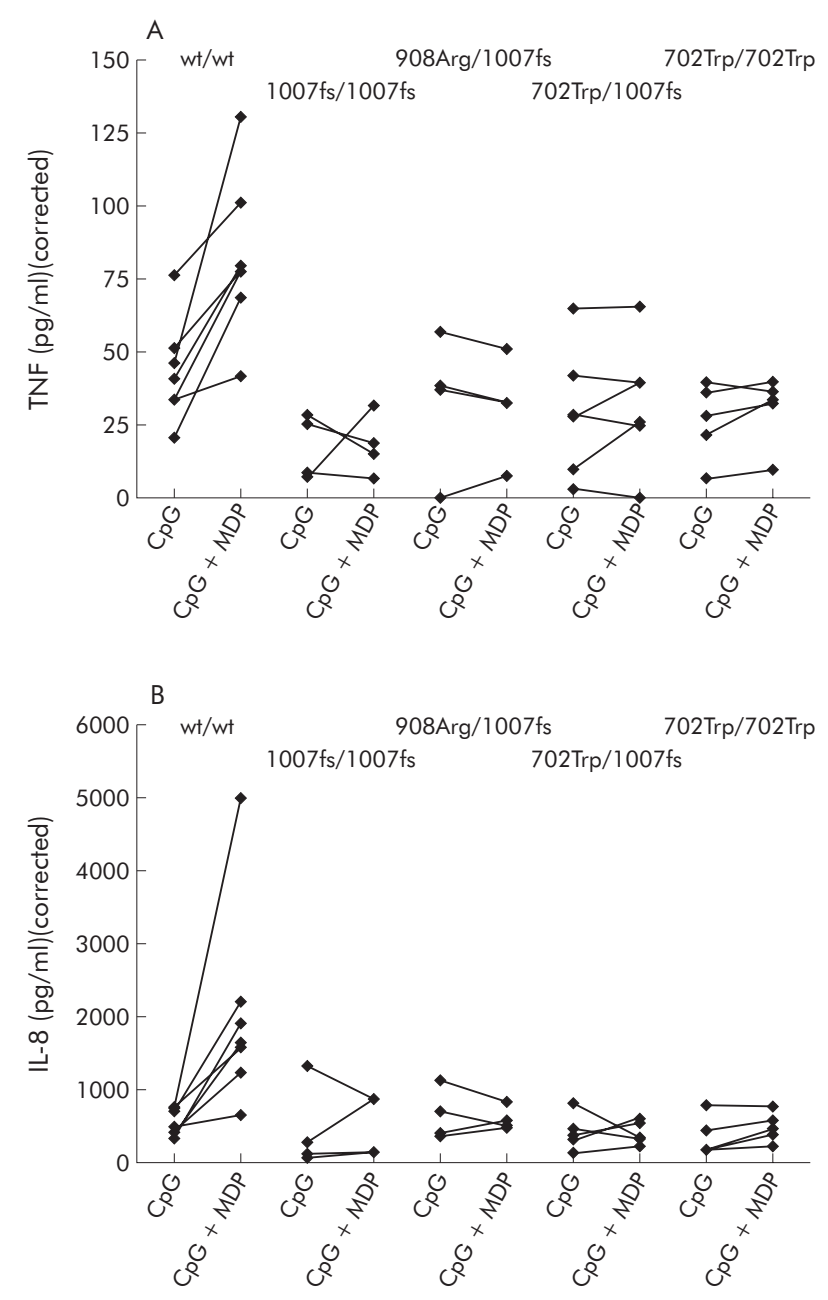

Figure 3 Synergistic interaction between CpG DNA and muramyl dipeptide (MDP) was lost in the presence of nucleotide binding oligomerisation domain 2 (NOD2) mutations. Peripheral blood mononuclear cells (PBMCs) from $n=7$ NOD2 wild-type healthy control individuals and $n=19$ NOD2 mutation homozygous Crohn's disease patients were stimulated with M362 CpG DNA $10 \mu \mathrm{g} / \mathrm{ml}$ and MDP $10 \mathrm{ng} / \mathrm{ml}$. Tumour necrosis factor $\alpha$ (TNF) (A) and interleukin 8 (IL-8) (B) were measured by enzyme linked immunosorbent assay. Mutant genotypes comprised 1007fs/1007fs $(n=4), 908 \mathrm{Arg} / 1007 \mathrm{fs}(n=4)$, $702 \operatorname{Trp} / 1007 \mathrm{fs}(\mathrm{n}=6)$, and 702Trp/702Trp $(n=5)$. Results are shown corrected by subtraction of respective media/MDP baseline responses.

consistent with an entirely recessive model with no true heterozygote effect in which some apparent heterozygous Crohn's cases are misclassified homozygotes (with a second unidentified mutation in the NOD2 pathway). ${ }^{16}$ In the current study, we did not test NOD2 wild-type Crohn's or inflammatory disease controls but the Crohn's double NOD2 mutant individuals studied had predominantly quiescent disease (table 1) and had similar responses to CpG DNA and LPS (also, other TLR ligands ${ }^{9}$ ) as wild-type controls. The observed differences between Crohn's double NOD2 mutants and wild-type controls after concomitant MDP stimulation are therefore unlikely to be confounding effects of active inflammation. We studied peripheral blood rather than intestinal lamina propria mononuclear cells (LPMCs) in the current study due to ease of collection. Similar proliferative responses to CpG DNA have been reported in LPMCs and PBMCs, ${ }^{17}$ and it will be of interest to study whether LPMC responses are also enhanced by NOD2 stimulation.

Innate immune signalling through TLR9 dependent recognition of bacterial CPG DNA has special importance in the gastrointestinal tract. Firstly, Rachmilewitz et al have suggested TLR9 signalling is essential in mediating the anti-inflammatory effects of probiotics (VSL-3, via the immunostimulatory CpG DNA component of the preparations), ${ }^{18}$ drugs currently being studied in pouchitis and for maintaining remission in inflammatory bowel disease. Secondly, although intestinal epithelial cell responses to some TLR ligands (for example, LPS) are markedly downregulated, TLR9 signalling is intact in intestinal epithelia. ${ }^{19}$ Paneth cells, which play an important role in protecting small intestine crypts through release of antimicrobial molecules, strongly express both NOD2 and TLR9 close to secretory granules in intracellular compartment. ${ }^{20} 21$ Injection of mice with CpG DNA led to a decrease in the number of large secretory granules, consistent with Paneth cell degranulation and defensin release. CpG DNA treatment also increased resistance to oral challenge with virulent Salmonella typhimurium. ${ }^{21}$ Despite the relevance of TLR9 signalling to intestinal inflammation and innate immunity, the concentration of CpG DNA in the intestinal lumen (or, for Paneth cell sensing, locally within crypts) is not known. In the current study, we therefore used a CpG DNA concentration similar to other published studies and as recommended by the supplier, having performed initial dose-response experiments.

In vivo, it is likely that innate immune pattern recognition receptors are not triggered one-at-once by single ligands but rather that complex activation of multiple receptors takes place due to the many TLR and NOD ligand motifs present on a microbial pathogen. ${ }^{122}$ In NOD2 associated Crohn's disease, failure to enhance TLR9 signalling by concurrent MDP/NOD2 sensing may permit pathogen invasion of the intestinal lumen (although whether the defect is in Paneth cell degranulation, epithelial cell, or macrophage/dendritic cell responses is unclear). Although conventional understanding is that TLR recognition triggers the innate immune system leading to an inflammatory response, a protective role of TLR activation by intestinal commensal bacteria has been demonstrated..$^{23}$ Under steady state conditions, activation of TLRs by commensal microflora was critical for tissue repair, and protection against intestinal injury and associated mortality. ${ }^{23}$ These data suggest studies of TLR signalling are of great relevance towards understanding mechanisms of both pathogenesis and therapeutics in inflammatory bowel disease.

There have been three recent reports of NOD2 and TLR function studied in gene targeted mouse models. Watanabe et al suggested that NOD2 mutant (targeted deletion of exon 1) mouse cells might show enhanced TLR2 mediated responses with MDP costimulation. ${ }^{24}$ Maeda et al generated mice with a targeted defect similar to the human 1007fs mutation, and demonstrated enhanced NFKB activation and IL- $1 \beta$ secretion in response to MDP in mutant mice. ${ }^{25}$ These effects are opposite to those found in the current study, and indeed synergistic effects between MDP and stimuli, including TNF- $\alpha$ and LPS, are now consistently described in human cells. $^{7-9} 16$ These human findings are also consistent with the report by Kobayashi et al of synergy between TLR ligands (although CpG DNA was not studied) and MDP in wild-type but not in mutant mice (targeted deletion of exon 3). ${ }^{26}$ Synergy in IL-8 production between MDP and CpG DNA in a human monocyte cell line has recently been independently confirmed $^{10}$ but concentrations of MDP 1000-fold higher than those used for primary cells in the current study were necessary to observe any effects. These comparisons suggest caution is necessary in extrapolating NOD2 functional data obtained in vitro or in vivo from mouse (versus human ${ }^{27}$ ) or cell line studies (versus primary cells). Studies on primary human cells will remain the most relevant to Crohn's disease. 
The mechanism of enhancement of TLR signalling by MDP/ NOD2 activation is unclear. Cell line studies suggested NOD2 interacts with RIP2 to activate NFאB. Cytokine production from mouse cells deficient in RIP2 is reduced on stimulation with LPS, peptidoglycan, or double stranded RNA but not bacterial CpG DNA, ${ }^{28}$ indicating that RIP2 is downstream of TLR2/3/4 but not TLR9. These data, taken together with our study showing NOD2 mediated enhancement of TLR9 responses in human cells, suggest a mechanism for the synergistic effect other than RIP2. A number of other NOD2 interacting proteins have been recently described (for example, CLAN, ${ }^{29} \mathrm{TAKl}{ }^{30} \mathrm{NALP} 3 /{ }^{\text {cryopyrin inflammasome, }}{ }^{31}$ and GRIM1932) which may be implicated. Dual signalling via both TLR and NOD pathways may be necessary for efficient innate immune responses-further detailed studies are needed to dissect the mechanism of NOD2 mediated enhancement of TLR signalling and the importance in vivo of the interaction.

In conclusion, NOD2 stimulation of human cells with MDP normally enhances TLR9 mediated innate immune responses to bacterial CpG DNA. This marked synergistic effect is lost in Crohn's disease patients homozygous for NOD2 mutations, with major implications for TLR mediated intestinal homeostasis and inflammatory responses to pathogens.

\section{ACKNOWLEDGEMENTS}

We thank all of individuals contributing blood samples; staff of the Gastroenterology Unit (University of Oxford), St Mark's Hospital, and Guy's Hospital for assistance with patient recruitment and NOD2 genotyping; Anna Lundberg for endotoxin assays; and Daiichi Pharmaceutical Company (Japan) for the gift of MDP-Lys ${ }_{18}$. The study was funded by the Hammersmith Hospitals Trustees Research Committee and a Wellcome Trust Clinician Scientist Fellowship (to $\mathrm{DAvH})$.

\section{Authors' affiliations}

D A van Heel, S Ghosh, K A Hunt, R J Playford, Intestinal Inflammation and Repair Group, Department of Gastroenterology, Imperial College London (Hammersmith Campus), UK

C G Mathew, Department of Medical and Molecular Genetics, Guy's King's and St Thomas' School of Medicine, London, UK

A Forbes, St Mark's Hospital, Imperial College London, Harrow, UK

D P Jewell, Gastroenterology Unit, University of Oxford, Gibson

Laboratories, Radcliffe Infirmary, Oxford, UK

Conflict of interest: None declared.

\section{REFERENCES}

1 Philpott DJ, Girardin SE. The role of Toll-like receptors and Nod proteins in bacterial infection. Mol Immunol 2004;41:1099-108.

2 Economou M, Trikalinos TA, Loizou KT et al. Differential effects of NOD2 variants on Crohn's disease risk and phenotype in diverse populations: a metaanalysis. Am J Gastroenterol 2004;99:2393-404.

3 Hugot JP, Chamaillard M, Zouali H, et al. Association of NOD2 leucine-rich repeat variants with susceptibility to Crohn's disease. Nature 2001:411:599-603.

4 Ogura $\mathrm{Y}$, Bonen DK, Inohara N, et al. A frameshift mutation in NOD2 associated with susceptibility to Crohn's disease. Nature 2001;411:603-6. 5 van Heel DA, McGovern DPB, Jewell DP. Crohn's disease: genetic susceptibility, bacteria and innate immunity. Lancet 2001;357:1902-4.

6 Lesage S, Zouali $\mathrm{H}$, Cezard JP, et al. CARD15/NOD2 mutational analysis and genotype-phenotype correlation in 612 patients with inflammatory bowel disease. Am J Hum Genet 2002;70:845-57.
7 Yang S, Tamai R, Akashi S, et al. Synergistic effect of muramyldipeptide with lipopolysaccharide or lipoteichoic acid to induce inflammatory cytokines in human monocytic cells in culture. Infect Immun 2001;69:2045-53.

8 Traub S, Kubasch N, Morath S, et al. Structural requirements of synthetic muropeptides to synergize with lipopolysaccharide in cytokine induction. J Biol Chem 2004;279:8694-700.

9 van Heel D, Ghosh S, Butler M, et al. Muramyl dipeptide and Toll-like receptor sensitivity in NOD2 associated Crohn's disease. Lancet 2005;365:1794-6.

10 Uehara A, Yang S, Fujimoto Y, et al. Muramyldipeptide and diaminopimelic acid-containing desmuramylpeptides in combination with chemically synthesized Toll-like receptor agonists synergistically induced production of interleukin-8 in a NOD2- and NOD1-dependent manner, respectively, in human monocytic cells in culture. Cell Microbiol 2005;7:53-61.

11 van Heel D, McGovern D, Cardon L, et al. Fine mapping of the IBDI locus did not identify Crohn's disease associated NOD2 variants: implications for complex disease genetics. Am J Med Genet 2002;111:253-9.

12 Hampe J, Cuthbert A, Croucher PJ, et al. Association between insertion mutation in NOD2 gene and Crohn's disease in German and British populations. Lancet 2001;357:1925-8.

13 Ahmad T, Armuzzi A, Bunce M, et al. The molecular classification of the clinical manifestations of Crohn's disease. Gastroenterology 2002; 122:854-66

14 Kreher CR, Dittrich MT, Guerkov R, et al. CD4+ and CD8+ cells in cryopreserved human PBMC maintain full functionality in cytokine ELISPOT assays. J Immunol Methods 2003;278:79-93.

15 Hartmann G, Battiany J, Poeck H, et al. Rational design of new CpG oligonucleotides that combine $B$ cell activation with high IFN-alpha induction in plasmacytoid dendritic cells. Eur J Immunol 2003;33:1633-41.

16 Li J, Moran T, Swanson E, et al. Regulation of IL-8 and IL-1 beta expression in Crohn's disease associated NOD2/CARD 15 mutations. Hum Mol Genet 2004; 13:1715-25

17 Jugde F, Boissier C, Birebent B, et al. Stimulation of peripheral blood and intestinal mucosa cells by synthetic $\mathrm{CpG}$ oligodeoxynucleotides. Hum Immunol 2004;65:218-30

18 Rachmilewitz D, Katakura K, Karmeli F, et al. Toll-like receptor 9 signaling mediates the anti-inflammatory effects of probiotics in murine experimental colitis. Gastroenterology 2004;126:520-8.

19 Akhtar M, Watson JL, Nazli A, et al. Bacterial DNA evokes epithelial IL-8 production by a MAPK-dependent, NF-kappaB-independent pathway. FASEB J 2003;17:1319-21.

20 Ogura Y, Lala S, Xin W, et al. Expression of NOD2 in Paneth cells: a possible link to Crohn's ileitis. Gut 2003;52:1591-7.

21 Rumio C, Besusso D, Palazzo M, et al. Degranulation of Paneth cells via tolllike receptor 9. Am J Pathol 2004;165:373-81.

22 Sansonetti PJ. War and peace at mucosal surfaces. Nat Rev Immunol 2004;4:953-64.

23 Rakoff-Nahoum S, Paglino J, Eslami-Varzaneh F, et al. Recognition of commensal microflora by toll-like receptors is required for intestinal homeostasis. Cell 2004;118:229-41.

24 Watanabe T, Kitani A, Murray PJ, et al. NOD2 is a negative regulator of Tolllike receptor 2-mediated Thelper type 1 responses. Nat Immunol 2004;5:800-8.

25 Maeda S, Hsu LC, Liu H, et al. Nod2 mutation in Crohn's disease potentiates NF-kappaB activity and IL-1 beta processing. Science 2005;307:734-8.

26 Kobayashi KS, Chamaillard M, Ogura Y, et al. Nod2-dependent regulation of innate and adaptive immunity in the intestinal tract. Science 2005;307:731-4.

27 Mestas J, Hughes CC. Of mice and not men: differences between mouse and human immunology. J Immunol 2004;172:2731-8

28 Kobayashi K, Inohara N, Hernandez LD, et al. RICK/Rip2/CARDIAK mediates signalling for receptors of the innate and adaptive immune systems. Nature 2002:416:194-9.

29 Damiano JS, Oliveira V, Welsh K, et al. Heterotypic interactions among NACHT domains: implications for regulation of innate immune responses. Biochem J 2004;381(Pt 1):213-19.

30 Chen CM, Gong Y, Zhang M, et al. Reciprocal cross talk between Nod2 and TAK1 signaling pathways. J Biol Chem 2004;279:25876-82.

31 Martinon F, Agostini L, Meylan E, et al. Identification of bacterial muramyl dipeptide as activator of the NALP3/cryopyrin inflammasome. Curr Biol 2004; 14:1929-34.

32 Barnich N, Hisamatsu T, Aguirre JE, et al. GRIM-19 interacts with nucleotide oligomerization domain 2 and serves as downstream effector of anti-bacterial function in intestinal epithelial cells. J Biol Chem 2005;280:19021-6.

33 Gasche C, Scholmerich J, Brynskov J, et al. A simple classification of Crohn's disease: report of the Working Party for the World Congresses of Gastroenterology, Vienna 1998. Inflamm Bowel Dis 2000;6:8-15. 